\title{
TETRACONAZOLE LEADS TO ALTERATIONS IN FUSARIUM GRAMINEARUM AT DIFFERENT MOLECULAR LEVELS
}

\author{
YÖRÜK, E. \\ Department of Molecular Biology and Genetics, Istanbul Yeni Yuzyll University \\ Istanbul, Cevizlibag, Turkey \\ (e-mail: emre.yoruk@yeniyuzyil.edu.tr; phone: +90-532-599-3325; fax: +90-212-481-4058) \\ (Received $6^{\text {th }}$ Jul 2018; accepted $31^{\text {st }}$ Aug 2018)
}

\begin{abstract}
The alterations in F. graminearum due to tetraconazole (TCZ) have been investigated in this study. The minimum inhibitory concentration (MIC), and inhibitory concentrations $50 \%$ and $25 \%\left(\mathrm{IC}_{50}\right.$ and $\mathrm{IC}_{25}$ ) were obtained by adding different concentrations of TCZ to potato dextrose agar (PDA). MIC, $\mathrm{IC}_{50}$ and $\mathrm{IC}_{25}$ values were detected as 32,16 and $8 \mu \mathrm{g} / \mathrm{mL}$ TCZ. Epigenetic changes have been evaluated via genomic template stability (GTS) by the RAPD and CRED-RA methods. GTS values were recorded as $86.73 \%$ and $85.71 \%$ in $\mathrm{IC}_{50}$ and $\mathrm{IC}_{25}$ sets. A total of 157 bands were obtained via RAPD. The average $\%$ polymorphism values of $\mathrm{HapII}$ and $\mathrm{MspI}$ digested samples were detected as 5.72 and 5.37 with 4.68 and $2.6 \%$ for $\mathrm{IC}_{25}$ and $\mathrm{IC}_{50}$ groups, respectively. The expression levels of genes related to apoptosis $(H o g 1)$, cell stability (Mgv1), oxidative stress $(P O D)$ and deoxynivalenol production (tri5) in the control and the experiment sets were investigated by qPCR. Increased concentrations of TCZ lead to upregulation in Hogl, Mgvl and POD genes whereas down regulation was recorded in tri5 expression. The late apoptosis and oxidative stress were detected via the acridine orange-ethidium bromide (AoEb) and the DCF-DA staining assays. The findings showed that TCZ could lead to damage on phytopathogenic fungi at genomic, epigenetics, transcriptomics and apoptotic levels.
\end{abstract}

Keywords: apoptosis, epigenetics, fungicide, genomic stability, oxidative stress

\section{Introduction}

Fusarium graminearum species complex is a worldwide important phytopathogenic species. F. graminearum is predominating causal agent of fusarium head blight (FHB) disease in humid and semi-humid areas. The FHB results in destructive affects in fields related to economically important cereals such as wheat, barley and maize (Goswami and Kistler, 2005; Miedaner et al., 2008). Annual economic losses reach up to millions of dollars only in the USA and China (Lori et al., 2009; Matny, 2015). Epidemics result in products with reduced quality and quantity. Also, deoxynivalenol, zearalenone and some other minor mycotoxins contamination of cereals have been detected in the fields related to FHB worldwide (Miedaner et al., 2008; Pasquali et al., 2016). FHB and the related mycotoxins lead to several kinds of negative effects on human health and struggle with major agent of FHB, $F$. graminearum, is a preliminary step in disease management.

$F$. graminearum is a homothallic fungus with asexual ( $F$. graminearum) and sexual (Gibberella zeae) stages (Kerényi et al., 2004). High levels of genotypic and morphological diversity have been reported for $F$. graminearum. 16 members for this species complex have been identified by the morphological and multiloci genotyping analysis (Aoki and O'Donnell, 1999; O'Donnell et al., 2004; Miedaner et al., 2008; Sarver et al., 2011; Przemieniecki et al., 2015). The species also shows high levels of variation in host, chemotype and aggressiveness worldwide (Pasquali and Migheli, 2014). These and some features of $F$. graminearum make it popular phytopathogen and also allow it to become a model organism in molecular plant pathology research area. 
The genome of $F$. graminearum $\mathrm{PH}-1$ strain has been sequenced and annotated. Up to 14.000 genes are identified by bioinformatics analysis and comparative data for ESTs, DNA markers, gene clusters related to mycotoxin production or genes associated with secondary metabolite biosynthesis pathways have been well characterized (King et al., 2017). The knowledge on genome structure of $F$. graminearum shows that it would facilitate further molecular genetics studies about FHB.

Struggle with FHB and $F$. graminearum have been maintained by different approaches worldwide. The development of disease-resistant plant cultivars or genetically modified plants, the antagonistic microorganisms' usage and the fungicide treatment are currently the most popular strategies. However, the development of resistant plants or antagonistic microorganism usage have some possible disadvantages such as prolonged periods, laborious assays, non-cost-effective processes, low agronomic traits and poor results (Dal-Bello et al., 2002; Anand et al., 2003; Bai and Shaner, 2004; Bernardo et al., 2007). However, the usage of fungicides has become the most popular and the most effective strategy in fighting with FHB worldwide. Several common types of fungicides including benzimidazole class and demethylation inhibitors have been used in disease management worldwide. However, the fungicide application does not present successful results in the fields, where they have been used. Particularly, the antifungal resistant development has been reported for those chemical compounds in many regions of the world. The logic behind the poor results in disease management and fungicide resistance development have been related to high level of genetic diversity among the populations of $F$. graminearum species complex. The failure in fungicide application and fungicide resistance have been shown by genetic and phenotypic analysis. Isolates with MIC values higher than $10 \mu \mathrm{g} / \mathrm{mL}$ for azole derivatives have been detected in $F$. graminearum species complex isolates by the agar dilution technique. The point mutations in $\beta$-tubulin and cyp51 genes leading to the fungicide resistance have been detected. Time management and climatic changes in agro-ecological regions where FHB present have also become related to failure related to fungucide application (Chung et al., 2008; Talas and McDonald, 2015; Qian et al., 2018; Yang et al., 2018). However, investigations associated with alterations in molecular levels in fungicide treated fungi could provide additional and extra point of view for disease management. In this study, it was aimed to detect the effects of tetraconazole (TCZ; one of the most common azole derivative used in disease management worldwide) on $F$. graminearum have been evaluated at epigenetics, transcriptomics and cellular levels by different approaches..

\section{Materials and methods}

\section{Fungal material and phenotypic tests}

F. graminearum $\mathrm{H}-11$ strain which is isolated from the diseased rice sample was provided from Dr. Theresa Lee from Seoul National University (Lee et al., 2001). The experimental steps of this study were carried out in Turkey. The fungal control sets were grown on potato dextrose agar/broth (PDA/PDB) for 7 days at $26 \pm 2{ }^{\circ} \mathrm{C}$ (PDA: Hi-Media, India) at controlled growth chamber (Nüve, Turkey). Experimental groups were grown on PDA/PDB amended with different concentrations of TCZ $(2,4,8,16$ and $32 \mu \mathrm{g} / \mathrm{mL}$ ) (Sigma, U.S.A.). The $0.25 \mathrm{~cm}^{2}$ mycelial plugs were used for obtaining fresh cultures. Minimum inhibitory concentration (MIC), inhibitory concentration 50\% and $25 \%\left(\mathrm{IC}_{50}\right.$ and $\left.\mathrm{IC}_{25}\right)$ values were detected by the agar dilution technique and the 
linear growth rates (LGR) were calculated by the measurement of radial growth of fungal cultures as mm day ${ }^{-1}$ at 4 th and 7 th days of incubation.

Genomic DNA (gDNA) extraction, RAPD (random amplified polymorphic DNA) and CRED-RA (coupled restriction enzyme digestion-random amplification) analysis

gDNA was extracted from the 7-day-old $F$. graminearum cultures of experiment sets. $100 \mathrm{mg}$ mycelia was homogenized with liquid nitrogen, sterile pestle and mortar. $500 \mu \mathrm{L}$ of lysis buffer $(100 \mathrm{mM}$ Tris $\mathrm{HCl}, 100 \mathrm{mM}$ EDTA, $1 \mathrm{M} \mathrm{NaCl}, 1 \%$ SDS and 1/500: v/v: $\beta$-mercaptaethanol) was added and the homogenization was completed. Then, the sodium dodecyl sulphate-based protocol was followed (Niu et al., 2008; Yörük et al., 2016). Qualitative and quantitative analyses were performed via 1\% agarose gels and spectrophotometer (Thermo, U.S.A.).

RAPD and CRED-RA methods were used in the genomic template stability and epigenetic profiling of TCZ treated and non-treated $F$. graminearum. A routine RAPD protocol (Yörük and Albayrak, 2013) was used in GTS assays of non-digested control, MspI-digested, HapII-digested experiment sets by using thermal cycler (Hi-Media, India). The total of 20 RAPD primers were used in this study (Table 1).

Table 1. RAPD primers used in this study and total band numbers obtained in RAPD analysis

\begin{tabular}{|c|c|c|c|}
\hline Primer & Sequence $\left(5^{\prime}-3^{\prime}\right)$ & $\%$ GC & Total band no \\
\hline OPA- 03 & AGTCAGCCAC & $60 \%$ & 11 \\
\hline OPA-04 & AATCGGGCTG & $60 \%$ & - \\
\hline OPA-05 & AGGGGTCTTG & $60 \%$ & - \\
\hline OPA-07 & GAAACGGGTG & $60 \%$ & 13 \\
\hline OPA-08 & GTGACGTAGG & $60 \%$ & 12 \\
\hline OPA-01 & CAGGCCCTTC & $70 \%$ & 12 \\
\hline OPA-02 & TGCCGAGCTG & $70 \%$ & 8 \\
\hline OPA-06 & GGTCCCTGAC & $70 \%$ & - \\
\hline OPA-09 & GGGTAACGCC & $70 \%$ & 8 \\
\hline OPA-13 & CAGCACCCAC & $70 \%$ & 10 \\
\hline OPB-06 & TGCTCTGCCC & $70 \%$ & 9 \\
\hline OPB-07 & GGTGACGCAG & $70 \%$ & 10 \\
\hline OPB-10 & CTGCTGGGAC & $70 \%$ & 10 \\
\hline OPB-13 & TTCCCCCGCT & $70 \%$ & 11 \\
\hline OPC-5 & GATGACCGCC & $70 \%$ & 9 \\
\hline OPC-4 & CCGCATCTAC & $60 \%$ & 9 \\
\hline OPB-19 & ACCCCCGAAG & $70 \%$ & 7 \\
\hline OPB-14 & TCCGCTCTGG & $70 \%$ & 8 \\
\hline OPC-07 & GTCCCGACGA & $70 \%$ & 10 \\
\hline
\end{tabular}

gDNA digestion was carried out in $20 \mu \mathrm{L}$ mixture including: $1 \mathrm{X}$ digestion buffer, $20 \mathrm{U}$ of digestion enzyme (Takara, Japan) and $250 \mathrm{ng} / \mu \mathrm{L}$ gDNA. The incubation for digestion was carried out at $37^{\circ} \mathrm{C}$ for $1 \mathrm{~h}$ in the thermal cycler. The digested (and also non-digested) samples were used in CRED-RA assays. PCR bands were 
electrophoresed on $1.7 \%$ agarose gels and captured via UV light using a transilluminator (Hi-Media, India). The genomic template stability (GTS \%) and the polymorphisms $\%$ for methylation was calculated as reported previously (Nardemir et al., 2015). The amplified bands were scored according to their presence (1) or absence (0). A similarity matrix and dendrogram were obtained from Nei-Li's coefficient (Nei and $\mathrm{Li}, 1979$ ) and the unweighted pair group method with arithmetic average algorithm (UPGMA) by using MVSP 3.1 software, respectively.

\section{Total RNA extraction and cDNA synthesis}

Total RNA molecules were extracted using Tri-Pure reagent (Roche, Switzerland) from seven days old culture. $50 \mathrm{mg}$ of mycelium was homogenized with $0.5 \mathrm{~mL}$ TriPrure reagent by using sterile mortar and pestle. The manufacturer's recommendations were then followed in the binding, washing and elution steps (Thermo, USA). The RNAs were evaluated as described as in gDNA analysis.

After RNA isolation, total RNAs were immediately converted to cDNA molecules. $2 \mu \mathrm{g}$ total RNA was used as starting amount. cDNAs were obtained by using one step commercial kit (Takara, Japan) by using the thermal cycler. The manufacturer's recommendations about thermal cycling and reaction mixtures were used in cDNA synthesis. cDNA molecules cDNAs were diluted as $1 / 4$ for gene expression analysis and used in the qPCR (quantitative polymerase chain reaction; real time PCR) analysis.

\section{Gene expression assays}

qPCR assays were used in the expression analysis of the Hogl (apoptosis related putative MAP kinase; DQ065608.1), Mgv1 (MAP kinase; AF492766.1), POD (peroxidase; XM_011329011.1) and tri5 (Trichodiene synthase; EF661664.1) genes. The housekeeping gene was the $\beta$-tubulin (AY303689.1). Primers (Table 2) were designed via Primer 3 software and checked via the olygoanalyzer tool of the Integrated DNA Technologies.

Table 2. Primers related to gene expression analysis used in this study

\begin{tabular}{c|c|c}
\hline Primer & Primer sequence (5'-3') & Band size (bp) \\
\hline betaF/betaR & agggtcattacaccgagggt / gtaccaccaccaagagagtgg & 121 \\
\hline MgvRTF/MgvRTR & aggttcaacgattccgacag / gaccattaccctgaggcaga & 100 \\
\hline FusHog1F/FusHog1R & cctggcaaaaatacgacgtt / tgatggagaattggttgacg & 117 \\
\hline FusPodrtF/FusPodrtR & tggatcaaggacattggtga / gttggtagcatcctgctggt & 117 \\
\hline tri5fullF/tri5fullR & atggagaactttccaccgagtatt / agtccatagtgctacggataaggttcaa & 469 \\
\hline
\end{tabular}

In qPCR assays, the target gene expressions were normalized according to the housekeeping gene expression by using the $2^{-\Delta \Delta C T}$ formula (Livak and Schmittgen, 2001). The $\mathrm{Cp}$ (crossing point), $\Delta \mathrm{CT}, \Delta \Delta \mathrm{CT}, 2^{-\Delta \Delta \mathrm{CT}}$ values were recorded and calculated using the software provided by Roche LightCycler 480 II system (Roche, Switzerland). The one step Sybr Green I master mix kit (Takara, Japan) was used in qPCR assays. qPCRs were carried out in $12 \mu \mathrm{L}$ reaction volume with $1 \mathrm{X}$ Sybr Green I mix, 0.5 pmol primers and $2 \mu \mathrm{L}$ of cDNA corresponding to $0.5 \mu \mathrm{g}$ total RNA. Cycling 
conditions, standard dilutions of $4 \log$ phases and the melting curve analysis were carried out as described by Yörük et al. (2018a). Experiments were replicated at least three times. Statistical analyses were performed via One Way ANOVA Analysis with Tukey's post-hoc test (GraphPad Prism 5.0, USA).

\section{Acridine orange/ethidium bromide (AO/EB) fluorescent staining}

The apoptotic and oxidative stress stemming from alteration in $F$. graminearum which is related to the TCZ treatment was evaluated via fluorescent microscopy. The determination early and/or late apoptosis and potential oxidative stress/reactive oxygen species (ROS) were investigated using Acridine Orange/Ethidium Bromide (AO/EB) and 2',7'-Dichlorofluorescin diacetate (DCF-DA) staining, respectively. $F$. graminearum cultivated on PDB supplemented with $\mathrm{TCZ}$ ( $\mathrm{IC}_{50}$ and $\mathrm{IC}_{25}$ concentrations) were used in the fluorescence detection.

In AO/EB dual staining assays, mycelia were obtained in $1 \mathrm{X}$ Phosphate buffered saline buffer (PBS) of $2 \mathrm{~mL}$ (Leiter et al., 2005). The mycelia were then fixed with $4 \%$ paraformaldehyde and $0.1 \%$ Triton $\mathrm{X}-100$ at least $30 \mathrm{~min}$ at $25{ }^{\circ} \mathrm{C}$. The cells were centrifuged at $14.000 \mathrm{rpm}$ for $5 \mathrm{~min}$. The cells were washed with $1.5 \mathrm{~mL} 1 \mathrm{X}$ PBS twice. $5 \mu \mathrm{L} \mathrm{AO} / \mathrm{EB}\left(60 \mu \mathrm{g} \mathrm{mL} \mathrm{m}^{-1} / 100 \mu \mathrm{g} \mathrm{mL}^{-1}\right)$ was added onto cells. The mixture was incubated at $25^{\circ} \mathrm{C}$ for $5 \mathrm{~min}$. After staining, the cells were washed with $1 \mathrm{~mL}$ of $1 \mathrm{X}$ PBS twice and then the cells were solved in $100 \mu \mathrm{L} 1 \mathrm{X}$ PBS. Dual staining was managed with fluorescence microscope (Carl Zeiss, Germany) with green fluorescent protein (GFP; AO 502ex/526em nm, EB 510ex/595em nm) and Texas RED (595ex/613em nm).

In ROS detection assays, TCZ treated and non-treated cells were suspended in PDB including $5 \mu \mathrm{g} / \mathrm{mL}$ DCF-DA for $15 \mathrm{~min}$. The cells were washed with $1 X$ PBS and the fluorophore was excluded as mentioned above. ROS detection was carried out via the FITC filter (494ex/518em $\mathrm{nm})$. The significant differences for fluorescence analysis were evaluated as described in qPCR assays.

\section{Results}

\section{TCZ resistance}

$F$. graminearum $\mathrm{H}-11$ showed both mycelial and also conidial growth in PDA media supplemented with 2, 4, 8 and $16 \mu \mathrm{g} / \mathrm{mL}$ TCZ. MIC concentration was detected as $32 \mu \mathrm{g} \mathrm{mL}{ }^{-1}$ TCZ. The $\mathrm{IC}_{50}$ and $\mathrm{IC}_{25}$ values were detected as 16 and $8 \mu \mathrm{g} / \mathrm{mL} \mathrm{TCZ}$. These concentrations of TCZ were used in the further analysis.

\section{GTS and epigenetics profiles}

The total of 20 primers were used in both RAPD and CRED-RA analysis. Three of these primers (OPA-04, OPA-05 and OPA-06) yielded no amplicon. Remaining 17 primer gave PCR bands in nine experiment sets comprising non-digested, HapIIdigested and MspI-digested groups of TCZ untreated, TCZ treated with $\mathrm{IC}_{25}$ and TCZ treated with $\mathrm{IC}_{50}$ sets.

In GTS analysis, 108 bands were obtained from the non-digested sets of $\mathrm{IC}_{50}, \mathrm{IC}_{25}$ and control groups by using 17 primers. The minimum and maximum band numbers were obtained from OPB19 with 3 bands and OPA07 with 13 bands (Fig. 1). The GTS values were detected as $86.73 \%$ and $85.71 \%$ for the $\mathrm{IC}_{25}$ and $\mathrm{IC}_{50}$ groups. These data 
showed that the TCZ treatment (with increased concentrations) lead to a potential decrease in genomic stability.

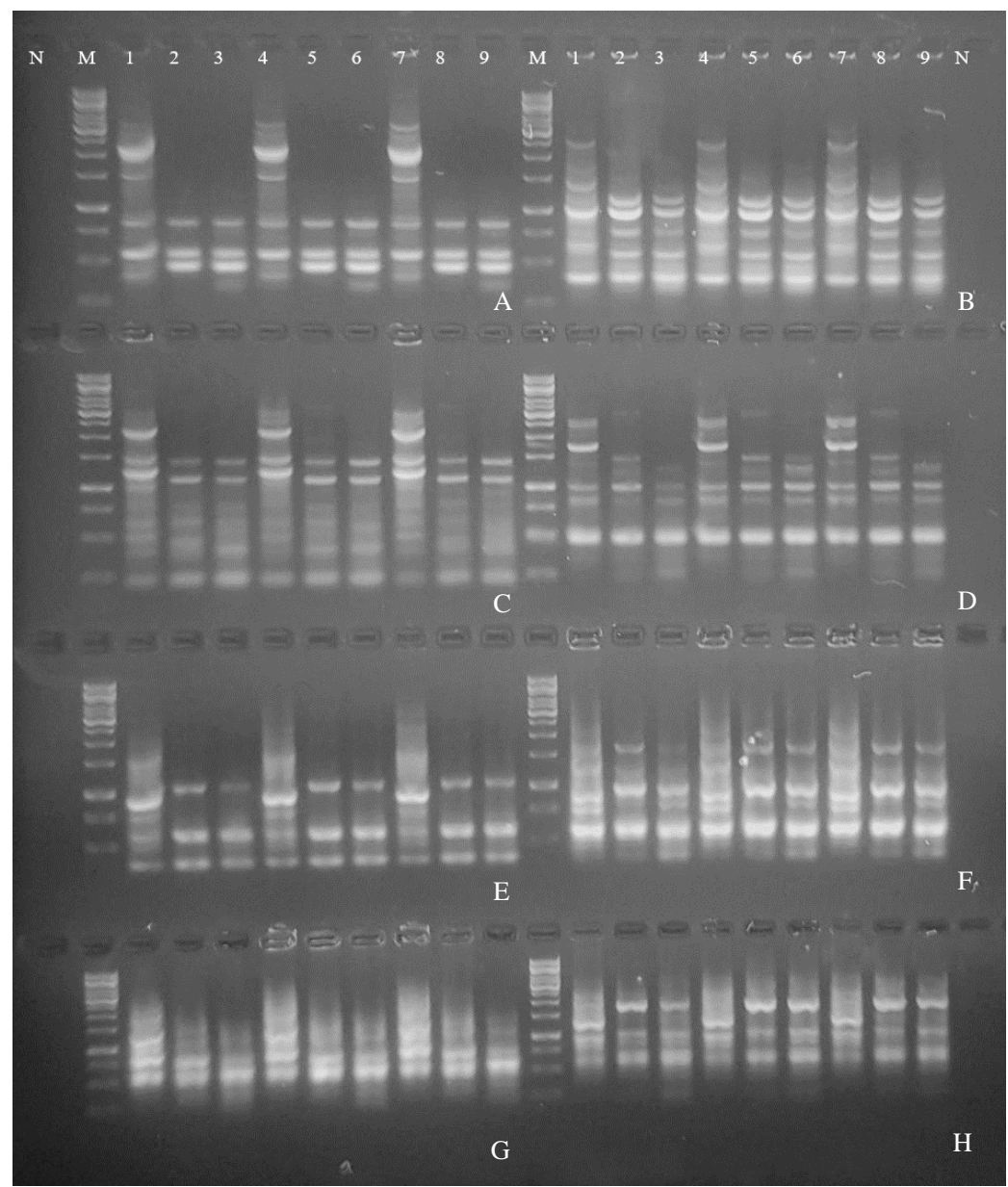

Figure 1. RAPD and CRED-RA profiles obtained from primers OPAO1 (A), OPAO3 (B), OPA07 (C), OPA08 (D), OPA09 (E), OPA02 (F), OPA13 (G), and OPAC7 (H), M: $1 \mathrm{~kb}$ DNA ladder

(Genemark, Taiwan), 1: control non-digested, 2: control HapII digested, 3: control MspI digested, 4: IC25 TCZ-treated non-digested, 5: IC25 TCZ-treated HapII digested, 6: IC25 TCZtreated MspI digested, 7: IC50 TCZ-treated non-digested, 8: IC50 TCZ-treated HapII digested,

9: IC50 TCZ-treated MspI digested samples. N: no template control

As well as in GTS analysis, 17 RAPD primers gave amplicon from each experiment set in CRED-RA analysis. Results showed that there were Type II and Type III epigenetics alterations due to TCZ treatment. The epigenetic alterations related to HapII and MspI digestion profiles of IC50 and IC25 groups were given in Table 3.

The average polymorphisms for epigenetic alterations were ranged from 2.6 to $5.72 \%$ for HapII and MspI analysis. Polymorphic changes based on epigenetics alterations were characterized by the band intensity and the loss or addition of a band. Additionally, the conventional band presence/absence analysis of Nei \& Li's coefficient showed that the minimum and the maximum genetic similarity values were as $40.86 \%$ and $97.98 \%$ in nine experimental groups. Genetically the most similar samples were belonged to the same enzyme digestion or the non-digestion sets for each experimental sets (Table 4). 
Table 3. Bands profiling obtained from CRED-RA analysis

\begin{tabular}{|c|c|c|c|c|c|c|c|c|c|c|c|c|c|c|}
\hline \multirow{3}{*}{ Primer } & \multirow{2}{*}{\multicolumn{2}{|c|}{ Control }} & \multicolumn{4}{|c|}{$\begin{array}{c}\text { Experiment total band } \\
\text { number }\end{array}$} & \multicolumn{4}{|c|}{$\begin{array}{c}\text { Experiment total } \\
\text { polymorphic band } \\
\text { number }\end{array}$} & \multicolumn{4}{|c|}{ Polymorphism (\%) } \\
\hline & & & \multicolumn{2}{|c|}{ IC25 } & \multicolumn{2}{|c|}{ IC50 } & \multicolumn{2}{|c|}{ IC25 } & \multicolumn{2}{|c|}{ IC50 } & \multicolumn{2}{|c|}{ IC25 } & \multicolumn{2}{|c|}{ IC50 } \\
\hline & HapII & MspI & HapII & MspI & HapII & MspI & HapII & MspI & HapII & MspI & HapII & MspI & HapII & MspI \\
\hline OPA1 & 3 & 5 & 3 & 5 & 3 & 5 & 0 & 0 & 0 & 0 & 0 & 0 & 0 & 0 \\
\hline OPA3 & 6 & 6 & 6 & 6 & 6 & 6 & 0 & 0 & 0 & 0 & 0 & 0 & 0 & 0 \\
\hline OPA7 & 6 & 6 & 6 & 6 & 6 & 7 & 1 & 0 & 1 & 0 & 16.67 & 0 & 16.67 & 0 \\
\hline OPA8 & 6 & 5 & 6 & 7 & 5 & 6 & 0 & 2 & 0 & 1 & 0 & 28.5 & 0 & 16.7 \\
\hline OPA9 & 3 & 3 & 3 & 3 & 3 & 3 & 0 & 0 & 0 & 0 & 0 & 0 & 0 & 0 \\
\hline OPA13 & 3 & 6 & 3 & 6 & 4 & 6 & 0 & 0 & 1 & 0 & 0 & 0 & 25 & 0 \\
\hline OPA2 & 4 & 3 & 4 & 4 & 4 & 4 & 0 & 1 & 0 & 1 & 25 & 25 & 0 & 25 \\
\hline OPC7 & 5 & 5 & 4 & 5 & 4 & 5 & 0 & 0 & 0 & 0 & 0 & 0 & 0 & 0 \\
\hline OPB6 & 5 & 5 & 5 & 5 & 5 & 5 & 0 & 0 & 0 & 0 & 0 & 0 & 0 & 0 \\
\hline OPB7 & 5 & 4 & 5 & 4 & 5 & 4 & 0 & 0 & 0 & 0 & 0 & 0 & 0 & 0 \\
\hline OPB10 & 6 & 5 & 6 & 5 & 6 & 5 & 0 & 0 & 0 & 0 & 0 & 0 & 0 & 0 \\
\hline OPB13 & 4 & 4 & 4 & 5 & 4 & 4 & 0 & 1 & 0 & 0 & 0 & 20 & 0 & 0 \\
\hline OPC5 & 7 & 7 & 7 & 6 & 7 & 6 & 0 & 0 & 0 & 0 & 0 & 0 & 0 & 0 \\
\hline OPC4 & 2 & 7 & 4 & 8 & 3 & 7 & 2 & 1 & 1 & 0 & 50 & 12.5 & 33.3 & 0 \\
\hline OPB19 & 4 & 5 & 4 & 4 & 4 & 4 & 0 & 0 & 0 & 0 & 0 & 0 & 0 & 0 \\
\hline OPB14 & 4 & 7 & 4 & 7 & 3 & 5 & 0 & 0 & 0 & 0 & 0 & 0 & 0 & 0 \\
\hline Mean & 4.56 & 5.19 & 4.625 & 5.38 & 4.5 & 5.13 & 0.1875 & 0.3125 & 0.1875 & 0.13 & 5.729 & 5.375 & 4.685625 & 2.6 \\
\hline
\end{tabular}

Table 4. Genetic similarity values related to non-digested, HapII digested or MspI digested control, $I C_{25}$ and $I C_{50}$ experiment sets

\begin{tabular}{|c|c|c|c|c|c|c|c|c|c|}
\hline & Control & Control/HapII & Control/MspI & $\mathbf{E C}_{25}$ & $\mathrm{EC}_{25} / \mathrm{HapII}$ & $\mathrm{EC}_{25} / \mathrm{MspI}$ & $\mathrm{EC}_{50}$ & $\mathrm{EC}_{50} /$ HapII & $\mathrm{EC}_{50} / \mathrm{MspI}$ \\
\hline Control & 100 & & & & & & & & \\
\hline Control/HapII & 54.971 & 100 & & & & & & & \\
\hline Control/MspI & 46.409 & 76.923 & 100 & & & & & & \\
\hline $\mathbf{E C}_{25}$ & 92.929 & 50.867 & 42.623 & 100 & & & & & \\
\hline $\mathrm{EC}_{25} / \mathrm{HapII}$ & 53.179 & 97.297 & 77.215 & 49.143 & 100 & & & & \\
\hline $\mathrm{EC}_{25} / \mathrm{MspI}$ & 44.565 & 77.987 & 95.858 & 40.86 & 79.503 & 100 & & & \\
\hline $\mathrm{EC}_{50}$ & 93 & 51.429 & 45.405 & 97.03 & 50.847 & 43.617 & 100 & & \\
\hline $\mathrm{EC}_{50} /$ HapII & 52.326 & 96.599 & 77.707 & 49.425 & 97.987 & 78.75 & 51.136 & 100 & \\
\hline $\mathrm{EC}_{50} / M s p I$ & 45.556 & 78.71 & 95.758 & 41.758 & 78.981 & 96.429 & 44.565 & 79.487 & 100 \\
\hline
\end{tabular}

\section{Gene expression analysis}

cDNA molecules were converted from total RNAs of high quality and quantity and then used in qPCR. In qPCR analysis, mean E values and melting scores (important markers for efficient qPCR experiments) were in the ranges of $2 \pm 0.2$ and $90 \pm 10 \%$, 
respectively. Minimum and maximum $\mathrm{Cp}$ values for the control and the experiment sets of b-tubulin, Hog1, Mgv1, POD, and tri5 genes were as 19.86 and 26.174, 19.53 and 24.7, 21.61 and 27.1, 20.19 and 24.8 with 21.58 and 26.74, respectively. Fold changes in Hog1, Mgvl, POD, tri5 expressions were recorded as $1.57 \pm 0.13(\mathrm{p}>0.05)$, $1.44 \pm 0.28(\mathrm{p}>0.05), 1.56 \pm 0.27(\mathrm{p}>0.05)$ and $0.32 \pm 0.09(\mathrm{p}<0.001)$ for $\mathrm{IC}_{25}$ set, respectively (Fig. 2). Similarly, these values for Hog 1, Mgv1, POD and tri5 genes were as $2.31 \pm 0.55 \quad(\mathrm{p}<0.001), \quad 2.08 \pm 0.33 \quad(\mathrm{p}<0.01), \quad 2.08 \pm 0.33 \quad(\mathrm{p}<0.01)$ and $0.033 \pm 0.01(\mathrm{p}<0.001)$ for $\mathrm{IC}_{50}$ set $($ Fig. 2). Significant changes in gene expression was found in each gene for $\mathrm{IC}_{50}$ sets where as only in tri5 expression showed significant differences in $\mathrm{IC}_{25}$ set.
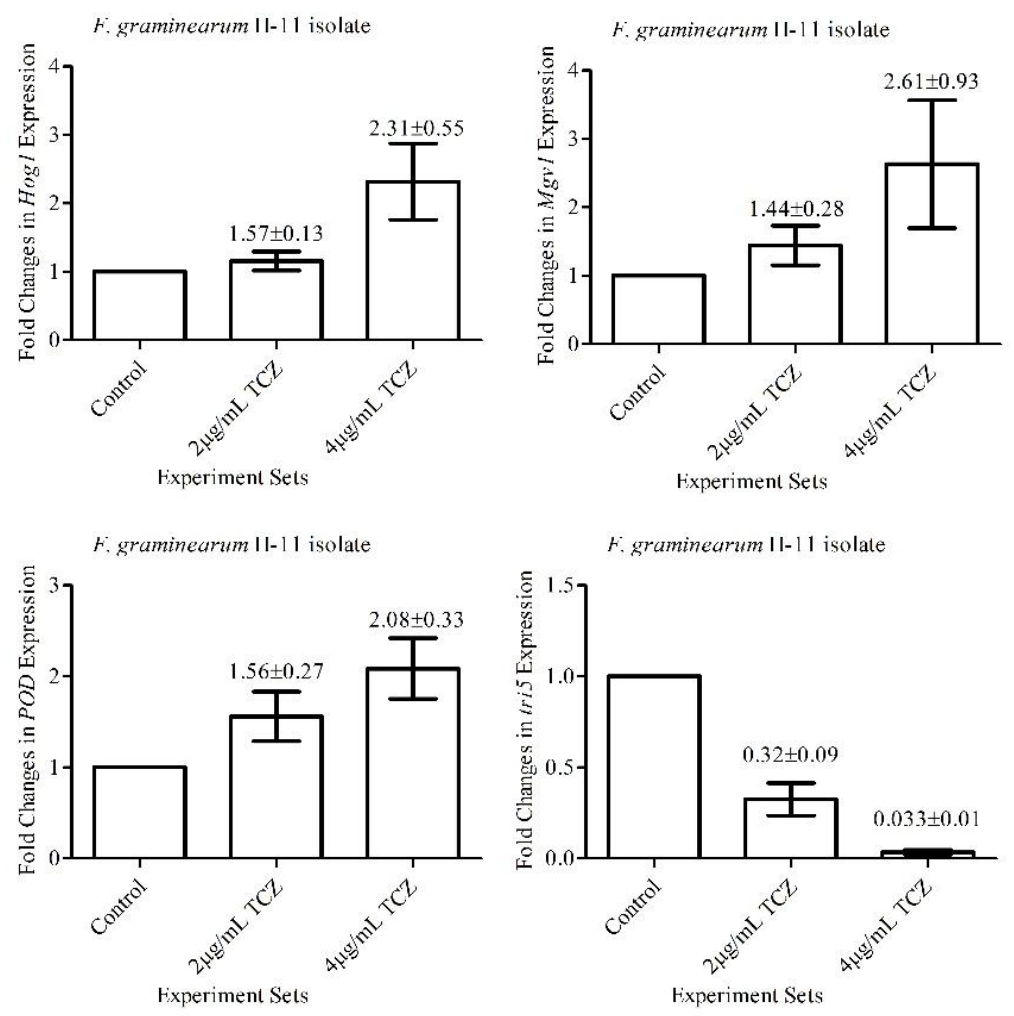

Figure 2. qRTPCR data of four target genes in the control and two experiment sets

\section{Fluorescence staining analysis}

The late apoptotic cells and the presence of oxidative stress were evaluated via the AoEb dual staining and the DCF-DA staining. In AoEb staining, both experiment sets showed apoptotic profiles while no yellow or orange painted cells were present in the control set. The fluorescence intensity of $\mathrm{EB}$ was higher (\%50) than $\mathrm{AO}$ in the experiment sets. The healthy cell percentages in $\mathrm{IC}_{25}$ and $\mathrm{IC}_{50}$ groups were $86.38 \pm 5.54$ and 77.19 \pm 9.91 , respectively (Fig. 3A, B). Significant differences in apoptotic cell levels were detected for $\mathrm{IC}_{25}(\mathrm{p}<0.05)$ and $\mathrm{IC}_{50}(\mathrm{p}<0.01)$ experimental sets.

Similarly, control set showed no fluorescent dye effect whereas the ROS activity was detected in the $\mathrm{IC}_{25}$ and $\mathrm{IC}_{50}$ groups via the DCF-DA staining (Fig. 3C, D). The healthy cell percentages were detected as $79.25 \pm 5.13(\mathrm{p}<0.01)$ and $72.2 \pm 3.81(\mathrm{p}<0.001)$ in $\mathrm{IC}_{25}$ and $\mathrm{IC}_{50}$ experimental sets, respectively. 


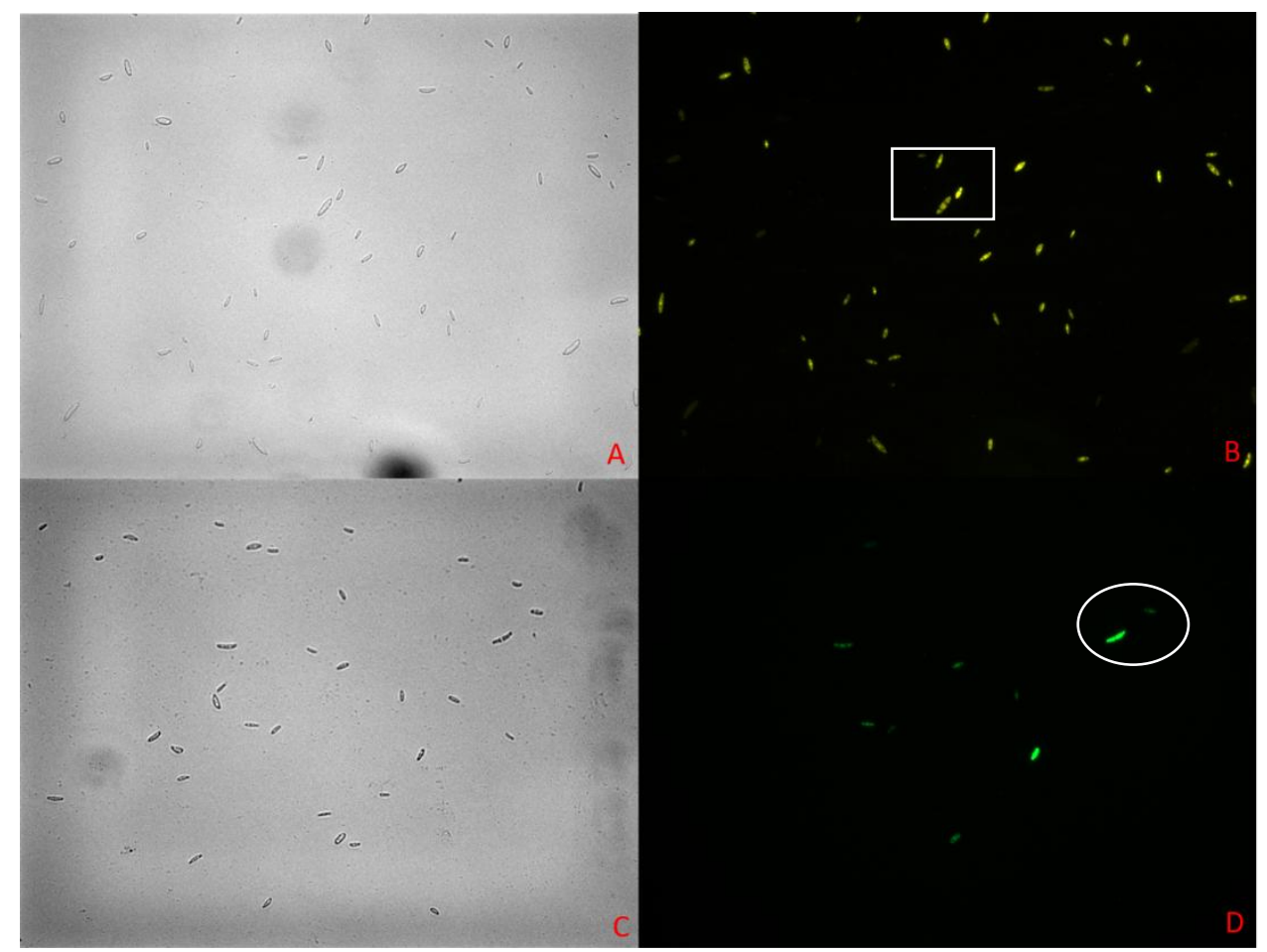

Figure 3. $A o E b(A$ and $B)$ and $D C F-D A(C$ and $D)$ staining profiles of $I C_{50}$ experiment set at $20 X$ magnification. $A$ and $C$ are of DIC filter photographs. $B$ and $D$ are belonging to AoEB with FITC filters, respectively. Cells in the square show the late apoptosis and cells with circle show the oxidative stress presence

\section{Discussion}

The alterations due to the TCZ on $F$. graminearum was investigated at different molecular levels in this study. TCZ is one of the major fungicide worldwide for many phytopathogenic species (Cools and Hammond-Kosack, 2013). MIC value for $F$. graminearum was recorded as $32 \mu \mathrm{g} / \mathrm{mL}$. It can be easily said that this level of fungicide could provide a powerful strategy to overcome the $F$. graminearum infections in the fields. Especially, if and when the MIC value is compared to the potential antifungal agents, the MIC values which could reach up to $1 \mathrm{mg} / \mathrm{mL}$ (Sefer et al., 2017; Yörük et al., 2018a), TCZ could be considered as a strong antimicrobial agent.

The common and powerful fungicides could lead to an antifungal resistance in the fields where they have been applied (Chung et al., 2008; Arif et al., 2009; Cools and Hammond-Kosack, 2013). The resistance to the common fungicides has been generally related to the genotypic variation, crop rotation, climatic conditions and some other characteristics related to the fungus and the host. However, the molecular basis has not been explained clearly and comprehensively. Responses of several phytopathogens to the specific antifungals have been investigated by several molecular genetics approaches such as the gene expression analysis, the oxidative stress and the apoptosis determination (Agus et al., 2018; Yörük et al., 2018a). However, those investigations present only limited data for antifungal resistance. In this study, the responses of $F$. graminearum to TCZ (which is harmful to the human health indirectly by feeding and drinking water supplies) have been evaluated at different molecular levels. The GTS and the CRED-RA analysis showed that this common antifungal could lead to 
alterations at the genomic and epigenomics levels. The long-term usage of TCZ could lead to more changes in GTS which can be a sign of genotypic diversity. Additionally, the transposable elements movement could be triggered by TCZ usage. GTS changes could result in high level of genomic variations, might lead to differentiation of novel species complex members. However, this kind of a suggestion needs further investigation. Epigenetics alterations have also been detected in this study. These results could serve as the turn on/off genes which could have a critical role in the fungal life cycle. Genetic engineering based tools such as the gene silencing and the gene replacement analysis could be used in further studies to support these findings.

TCZ usage led to the significantly important changes in the gene expression in $F$. graminearum. Upregulation of $\mathrm{Hog} 1, \mathrm{Mgvl}$ and $\mathrm{POD}$ genes in TCZ treated experiment set showed that the TCZ application could result in apoptosis like cell death and oxidative stress. Similarly, significant decrease in tri5 expression was detected in TCZ treated groups. Findings showed that TCZ could inhibit mycotoxin biosynthesis in addition to decrease in the fungal radial growth capacity. These genes or homologues have been used in different studies related to the apoptosis mechanism, downregulation of mycotoxin synthesis and the novel antifungal resistance etc. (Ponts et al., 2007; Sharon et al., 2009; Shlezinger, Goldfinger and Sharon, 2012; Sefer et al., 2017; Yörük et al., 2018b). However, in this study, it was claimed that the alterations in Hogl, Mgvl, $P O D$ and tri5 genes could be used as markers in revealing the detailed antifungal effects of any specific chemical compound. These antifungal effects could include a programmed cell death, oxidative stress, toxin inhibition, an abiotic stress response etc. Oxidative stress and programmed cell death like processes were also verified by the fluorescence microscopy analysis. Ethidium bromide penetrates into the cells with lost integrity and stains the cell as orange to red (McGahon et al., 1995). Similarly, the cells subjected to oxidative stress turn into green since DCF-DA is rapidly oxidized with ROS, and turn into the fluorescent DCF dye (Jou et al., 2004). The TCZ treated experimental sets showed that yellow-tan and green colored profiles with AoEb and DCF-DA, respectively. Both gene expression analysis and cellular display assays showed that TCZ is a potential abiotic stress factor for $F$. graminearum at different molecular levels.

The investigation of the effects of this TCZ on $F$. graminearum at molecular levels would provide useful data for the studies related to phytopathology. F. graminearum is hemi-biotrophic fungus with an asexual and a sexual reproduction. The species is accepted as major causal agent of head blight and crown rot of some economically important cereals worldwide (Miedaner et al., 2008; Matny, 2015). This popular enemy of field crops seem to be lose the against TCZ or some other common fungicides in many regions of the world. However, since resistance to common antifungals could be improved in the coming years, molecular responses of phytopathogens to antifungals should be clearly investigated. In this study, it was shown that TCZ could lead to alterations in $F$. graminearum at different molecular processes. However, the effects of TCZ on plant tissue cultures and the mammalian cell cultures should also be investigated in further studies.

\section{Conclusion}

The struggle with $F$. graminearum diseases have different approaches including the fungicide treatment as the most common protocol. The resistance to common 
antimicrobials has been known for many different microorganisms so far. In this study, it was shown that TCZ lead to mycelial growth inhibition, GTS changes, methylation alterations, oxidative stress and apoptosis like process. These changes at molecular processes could be responsible for the development of a resistance against common or specific antifungal compounds. However, further studies could include necrotrophic species, the plant tissue culture test, the mammalian cell culture tests, and genetic engineering confirmation etc. which also provide additional and supportive data related to plant pathology research area.

\section{REFERENCES}

[1] Agus, H. H., Sarp, C., Cemiloglu, M. (2018): Oxidative stress and mitochondrial impairment mediated apoptotic cell death induced by terpinolene in Schizosaccharomyces pombe. - Toxicology Research. DOI: 10.1039/c8tx00100f.

[2] Anand, A., Zhou, T., Trick, H. N,. Gill, B. S., Bockus, W. W., Muthukrishnan, S. (2003): Greenhouse and field testing of transgenic wheat plants stably expressing genes for thaumatin-like protein, chitinase and glucanase against Fusarium graminearum. - Journal of Experimental Botany 54(384): 1101-1111.

[3] Aoki, T., O'Donnell, K. (1999): Morphological and molecular characterization of Fusarium pseudograminearum sp. nov., formerly recognized as the Group 1 population of $F$. graminearum. - Mycologia: 597-609.

[4] Arif, T., Bhosale, J. D., Kumar, N., Mandal, T. K., Bendre, R. S., Lavekar, G. S., Dabur, R. (2009): Natural products-antifungal agents derived from plants. - Journal of Asian Natural Products Research 11(7): 621-638.

[5] Bai, G., Shaner, G. (2004): Management and resistance in wheat and barley to Fusarium head blight. - Annual Review of Phytopathology 42: 135-161.

[6] Bernardo, A., Bai, G., Guo, P., Xiao, K., Guenzi, A. C., Ayoubi, P. (2007): Fusarium graminearum-induced changes in gene expression between Fusarium head blightresistant and susceptible wheat cultivars. - Functional \& integrative Genomics 7(1): 6977.

[7] Chung, W. H., Ishii, H., Nishimura, K., Ohshima, M., Iwama, T., Yoshimatsu, H. (2008): Genetic analysis and PCR-based identification of major Fusarium species causing head blight on wheat in Japan. - Journal of General Plant Pathology 74(5): 364-374.

[8] Cools, H. J., Hammond-Kosack, K. E. (2013): Exploitation of genomics in fungicide research: current status and future perspectives. - Molecular Plant Pathology 14(2): 197210.

[9] Dal Bello, G. M., Monaco, C. I., Simon, M. R. (2002): Biological control of seedling blight of wheat caused by Fusarium graminearum with beneficial rhizosphere microorganisms. - World Journal of Microbiology and Biotechnology 18(7): 627-636.

[10] Goswami, R. S., Kistler, H. C. (2005): Pathogenicity and in planta mycotoxin accumulation among members of the Fusarium graminearum species complex on wheat and rice. - Phytopathology 95(12): 1397-1404.

[11] Jou, M-J., Peng, T-I., Reiter, RJ., Jou, S-B., Wu, H-Y., Wen, S-T. (2004): Visualization of the antioxidative effects of melatonin at the mitochondrial level during oxidative stress-induced apoptosis of rat brain astrocytes. - Journal of Pineal Research 37(1): 5570.

[12] Kerényi, Z., Moretti, A., Waalwijk, C., Oláh, B., Hornok, L. (2004): Mating type sequences in asexually reproducing Fusarium species. - Applied and Environmental Microbiology 70(8): 4419-4423.

[13] King, R., Urban, M., Hammond-Kosack, K. E. (2017): Annotation of Fusarium graminearum (PH-1) version 5.0. - Genome Announcements 5(2): e1479-16. 
[14] Lee, T., Oh, D. W., Kim, H. S., Lee, J., Kim, Y. H., Yun, S. H., Lee, Y. W. (2001): Identification of deoxynivalenol-and nivalenol-producing chemotypes of Gibberella zeae by using PCR. - Applied and Environmental Microbiology 67(7): 2966-2972.

[15] Leiter, É., Szappanos, H., Oberparleiter, C., Kaiserer, L., Csernoch, L., Pusztahelyi, T., Emri, T., Pocsi, I., Salvenmoser, W., Marx, F. (2005): Antifungal protein PAF severely affects the integrity of the plasma membrane of Aspergillus nidulans and induces an apoptosis-like phenotype. - Antimicrobial Agents and Chemotherapy 49(6): 2445-2453.

[16] Livak, K. J., Schmittgen, T. D. (2001): Analysis of relative gene expression data using real-time quantitative PCR and the $2^{-\Delta \Delta C T}$ method. - Methods 25(4): 402-408.

[17] Lori, G. A., Sisterna, M. N., Sarandón, S. J., Rizzo, I., Chidichimo, H. (2009): Fusarium head blight in wheat: impact of tillage and other agronomic practices under natural infection. - Crop Protection 28(6): 495-502.

[18] Matny, O. N. (2015): Fusarium head blight and crown rot on wheat \& barley: losses and health risks. - Advances in Plants \& Agricultural Research 2(39): 10-15406.

[19] McGahon, A. J., Martin, S. J., Bissonnette, R. P., Mahboubi, A., Shi, Y., Mogil, R. J., Nishioka, W. K., Green, D. R. (1995): The End of the (Cell) Line: Methods for the Study of Apoptosis in Vitro. - In: Prescott, D. M. (ed.) Methods in Cell Biology Vol. 46. Academic Press, Cambridge, MA, pp. 153-185.

[20] Miedaner, T., Cumagun, C. J. R., Chakraborty, S. (2008): Population genetics of three important head blight pathogens Fusarium graminearum, F. pseudograminearum and $F$. culmorum. - Journal of Phytopathology 156(3): 129-139.

[21] Nardemir, G., Agar, G., Arslan, E., Erturk, F. A. (2015): Determination of genetic and epigenetic effects of glyphosate on Triticum aestivum with RAPD and CRED-RA techniques. - Theoretical and Experimental Plant Physiology 27(2): 131-139.

[22] Nei, M., Li, W. H. (1979): Mathematical model for studying genetic variation in terms of restriction endonucleases. - Proceedings of the National Academy of Sciences 76(10): 5269-5273.

[23] Niu, C., Kebede, H., Auld, D. L., Woodward, J. E., Burow, G., Wright, R. J. (2008): A safe inexpensive method to isolate high quality plant and fungal DNA in an open laboratory environment. - African Journal of Biotechnology 7(16).

[24] O’Donnell, K., Ward, T. J., Geiser, D. M., Kistler, H. C., Aoki, T. (2004): Genealogical concordance between the mating type locus and seven other nuclear genes supports formal recognition of nine phylogenetically distinct species within the Fusarium graminearum clade. - Fungal Genetics and Biology 41(6): 600-623.

[25] Pasquali, M., Migheli, Q. (2014): Genetic approaches to chemotype determination in type B-trichothecene producing Fusaria. - International Journal of Food Microbiology 189: 164-182.

[26] Pasquali, M., Cocco, E., Guignard, C., Hoffmann, L. (2016): The effect of agmatine on trichothecene type B and zearalenone production in Fusarium graminearum, $F$. culmorum and F. poae. - PeerJ 4: e1672. DOI: 10.7717/peerj.1672.

[27] Ponts, N., Pinson-gadais, L., Barreau, C., Richard-forget, F. (2007): Exogenous $\mathrm{H}_{2} \mathrm{O}_{2}$ and catalase treatments interfere with Tri genes expression in liquid cultures of Fusarium graminearum. - FEBS Letter 581: 443-447.

[28] Przemieniecki, S. W., Kurowski, T. P., Korzekwa, K. (2015): Chemotypes and geographic distribution of the Fusarium graminearum species complex. - Environmental Biotechnology 10(2): 45-59.

[29] Qian, H., Du, J., Chi, M., Sun, X., Liang, W., Huang, J., Li, B. (2018): The Y137H mutation in the cytochrome P450 FgCYP51B protein confers reduced sensitivity to tebuconazole in Fusarium graminearum. - Pest Management Science 74(6): 1472-1477.

[30] Sarver, B. A. J., Ward, T. J., Gale, L. R., Broz, K., Kistler, H. C., Aoki, T., Nicholson, P., Carter, J., Donnell, K. O. (2011): Novel Fusarium head blight pathogens from Nepal and Louisiana revealed by multilocus genealogical concordance. - Fungal Genetics and Biology 48: 1096-1107. 
[31] Sefer, Ö., Yörük, E., Develi, E. S., Sezer, A. S., Konukcu, Z. (2017): Investigation of the effects of 2, 4-Dimethylpyrrole on Fusarium culmorum causal agent of head blight disease. - International Journal of Secondary Metabolite 4(2): 103-113. DOI: 10.21448/ijsm.307943.

[32] Sharon, A., Finkelstein, A., Shlezinger, N., Hatam, I. (2009): Fungal apoptosis: Function, genes and gene function. - FEMS Microbiology Reviews 33: 833-854.

[33] Shlezinger, N., Goldfinger, N., Sharon, A. (2012): Apoptotic-like programmed cell death in fungi: the benefits in filamentous species. - Frontiers in Oncology 2: 1-8.

[34] Talas, F., McDonald, B. A. (2015): Genome-wide analysis of Fusarium graminearum field populations reveals hotspots of recombination. - BMC Genomics 16: 1-13.

[35] Yang, Y., Li, M., Duan, Y., Li, T., Shi, Y., Zhao, D., Zhou, Z. (2018): A new point mutation in $\beta 2$ - tubulin confers resistance to carbendazim in Fusarium asiaticum. Pesticide Biochemistry and Physiology 145: 15-21. DOI: 10.1016/j.pestbp.2017.12.006.

[36] Yörük, E., Albayrak, G. (2013): Genetic characterization of Fusarium graminearum and $F$. culmorum isolates from Turkey by using random-amplified polymorphic DNA. Genetic Molecular Research 12(2): 1360-72.

[37] Yörük, E., Tunali, B., Kansu, B., Ölmez, F., Uz, G., Zümrüt, I. M., Sarıkaya, A., Meyva, G. (2016): Characterization of high-level deoxynivalenol producer Fusarium graminearum and $F$. culmorum isolates caused head blight and crown rot diseases in Turkey. - Journal of Plant Diseases and Protection 123(4): 177-186. DOI: 10.1007/s41348-016-0027-y.

[38] Yörük, E., Sefer, Ö., Sezer, A. S., Konukcu, Z., Develi, E. S. (2018a): Investigation of the Effects of Eugenol on Fusarium culmorum. - Iğdır University Journal of Institute of Science and Technology 8(2): 215-221.

[39] Yörük, E., Sefer, Ö., Tunali, B., Kansu, B., Sharifnabi, B., Yli-mattila, T. (2018b): Thiophanate methyl susceptibility and alterations in tri5, Mgvl and StuA expression among Fusarium graminearum and F. culmorum isolates. - Journal of Plant Pathology 1(9). DOI: 10.1007/s42161-018-0094-y. 